\title{
Extremely Low Ablation Rate of Metals Using XeCl Excimer Laser
}

\author{
Mitsuhiro Kusaba*1, Masaki Hashida ${ }^{* 2}{ }^{* 3}$, and Shuji Sakabe ${ }^{* 2, * 3}$ \\ ${ }^{* 1}$ Department of Electronics, Information and Communication Engineering, Osaka Sangyo \\ University, 3-1-1 Nakagaito, Daito, Osaka 574-8530, Japan \\ E-mail: kusaba@eic.osaka-sandai.ac.jp \\ *2 ICR Kyoto University, Gokasho, Uji, Kyoto 611-0011, Japan \\ ${ }^{* 3}$ Department of Physics, Graduate School of Science, Kyoto University, Kitashirakawa, Sakyo, \\ Kyoto 606-8502, Japan
}

\begin{abstract}
Ablation thresholds for the metallic elements Ti, Mo, Pt, Au, and Al were investigated using a $\mathrm{XeCl}$ excimer laser in the fluence range of $0.1-20 \mathrm{~J} / \mathrm{cm}^{2}$. The ablation thresholds were estimated from the dependence of the ablation rate and the diameter of the crater produced by the laser irradiation on laser fluence. Two ablation thresholds obtained from the ablation rate dependence on fluence agreed well with those obtained from the diameter dependence. The lower ablation threshold is related to the threshold calculated using a one-dimensional thermal diffusion model. The results suggest that even at such extremely low ablation rates, melting plays an essential role in excimer laser ablation.
\end{abstract}

DOI: 10.2961/jlmn.2018.01.0004

Keywords: laser ablation, ablation threshold, XeCl excimer laser, metal, ablation rate

\section{Introduction}

Laser ablation has various applications, such as observation of the target composition [1], removal of radioactive surfaces and small debris in spaces [2], and material processing of nanostructures [3-5]. To develop these applications, it is important to have more-accurate knowledge of laser ablation mechanisms. A large amount of both experimental and theoretical work has been done on laser ablation for metals [6-18]. In our previous experimental studies, the laser ablation rate (ablation depth per shot) of metals as a function of laser wavelength and pulse width (nanoseconds to femtoseconds) were reported [19-24]. We found that the ablation rate was related to the melting point of the target metal. It is known that the mechanisms for forming nanostructures by laser ablation depend on the laser irradiation conditions (e.g., wavelength, pulse width, number of pulses), the fluence, and the ablation threshold for material. In this work, we determine the ablation thresholds of the metallic elements Ti, Mo, Pt, $\mathrm{Au}$, and $\mathrm{Al}$ using a $\mathrm{XeCl}$ excimer laser.

\section{Experimental}

The experimental setup used to measure the ablation threshold is shown in Fig. 1. The samples used were mirror-polished metals of $\mathrm{Ti}, \mathrm{Mo}, \mathrm{Pt}, \mathrm{Au}$, and $\mathrm{Al}$. The samples were ablated using a $\mathrm{XeCl}$ excimer laser (COMPex 102; Lambda Physik) with an oscillation wavelength of $308 \mathrm{~nm}$ and a pulse width of $20.6 \mathrm{~ns}$ (full width at half-maximum). The laser was passed through an aperture with a diameter of $5 \mathrm{~mm}$. The laser fluence was controlled using an attenuator that comprised a polarizer and half-wave plate. The Gaussian beam profile shown in Fig. 2 was obtained using a spatial filter comprising a lens with a focal length of $1000 \mathrm{~mm}$ and an aperture with a diameter of $0.5 \mathrm{~mm}$. The sample was irradiated by focusing the beam using a lens with a focal length of $100 \mathrm{~mm}$.

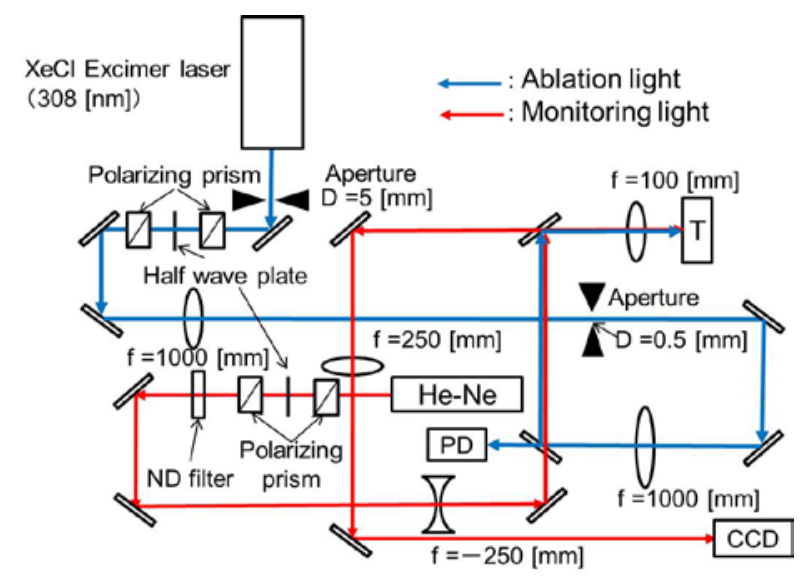

Fig. 1 Experimental setup using the $\mathrm{XeCl}$ excimer laser.

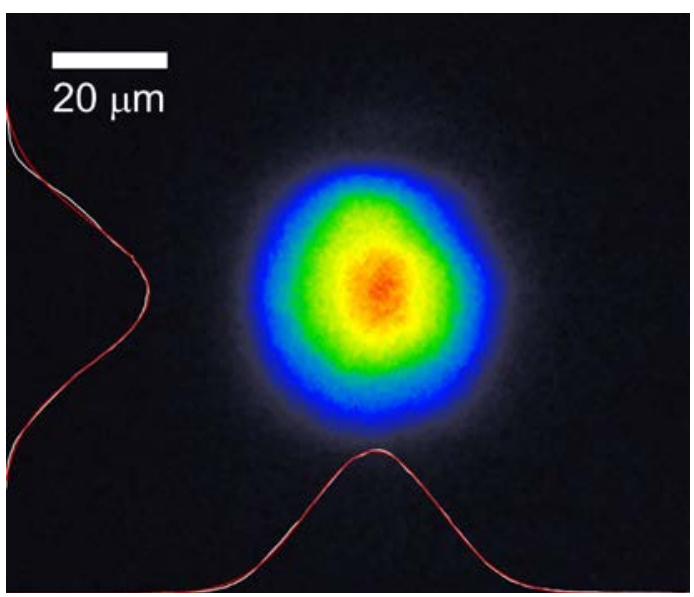

Fig. 2 Beam profile of the $\mathrm{XeCl}$ excimer laser. 
On the target surface, a laser spot size of around $40 \mu \mathrm{m}$ (full width at $\mathrm{e}^{-1}$ maximum) with Gaussian distribution was used for the ablation experiments. The laser energy (with stability of 12\%) and the number of pulses were adjusted in the ranges of $0.1-20 \mathrm{~J} / \mathrm{cm}^{2}$ (fluence) and 1-3000 shots, respectively. During ablation, the sample was irradiated by a He-Ne laser beam defocused using a lens with a focal length of $250 \mathrm{~mm}$.

The sample surface was observed in situ with a CCD camera (ARTCAM-150P5-BW-WOM-NCG; Artray). After laser ablation, the diameter and depth of craters produced on the surface of the sample were measured with a laser scanning microscope (VK-X250, Keyence).

\section{Results and discussion}

3.1 Estimation of ablation thresholds

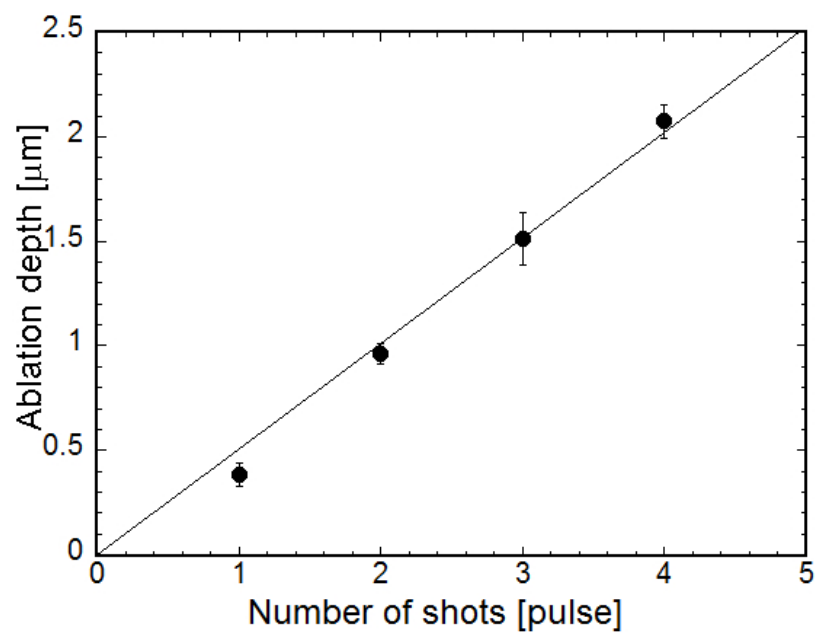

(a) Laser fluence at $12.3 \mathrm{~J} / \mathrm{cm}^{2}$

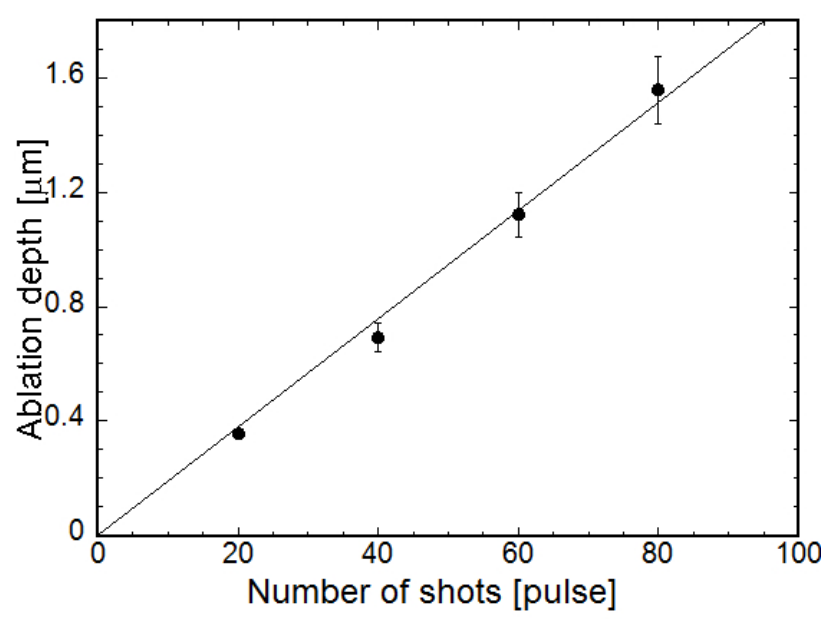

(b) Laser fluence at $2.30 \mathrm{~J} / \mathrm{cm}^{2}$

Fig. 3 Relationships between ablation depth and number of shots for Ti irradiated at fluences of (a) $12.3 \mathrm{~J} / \mathrm{cm}^{2}$ and (b) $2.30 \mathrm{~J} / \mathrm{cm}^{2}$.

The relationships between ablation depth and number of shots for Ti irradiated at fluences of $12.3 \mathrm{~J} / \mathrm{cm}^{2}$ and 2.30 $\mathrm{J} / \mathrm{cm}^{2}$ are shown in Fig. 3(a) and (b), respectively. The ablation depth was directly proportional to the number of shots and linear fits are shown in Fig. 3. The ablation rates were estimated from the slopes of the fitted lines and are plotted in Fig. 4 as a function of laser fluence. We estimated the ablation threshold from the measured dependences of the ablation rate and crater diameter on the laser fluence. The validity of this procedure has been confirmed by analyzing the ablation threshold for femtosecond laser ablation [25,26].

Figure 4 shows the ablation rate dependence on laser fluence for Mo. The ablation rate was calculated as the ablation depth per shot, and its dependence on the fluence is given by Eq. (1) [25-28]:

$$
R=\alpha^{-1} \ln \left(F / F_{\mathrm{th}}\right)
$$

where $R$ is the ablation rate [nm/pulse], $\alpha^{-1}$ is the penetration depth of light or thermal diffusion [nm], $F$ is the laser fluence of the ablation source $\left[\mathrm{J} / \mathrm{cm}^{2}\right]$, and $F_{\text {th }}$ is the ablation threshold $\left[\mathrm{J} / \mathrm{cm}^{2}\right]$. The ablation rates were fitted well with Eq. (1), as shown by the solid lines in Fig. 4. Two different ablation regions appeared in the laser fluence region of $0.1-20 \mathrm{~J} / \mathrm{cm}^{2}$. The lowest laser fluence at which the ablation rate could be measured, referred to here as the low ablation threshold $F_{\text {th,L, was }} 1.54 \mathrm{~J} / \mathrm{cm}^{2}$. At 6.35 $\mathrm{J} / \mathrm{cm}^{2}$, the ablation rate increased sharply, showing a different dependence on laser fluence from that at lower fluences. Therefore, the fluence of $F_{\mathrm{th}, \mathrm{H}}=6.35 \mathrm{~J} / \mathrm{cm}^{2}$ was identified as the high ablation threshold.

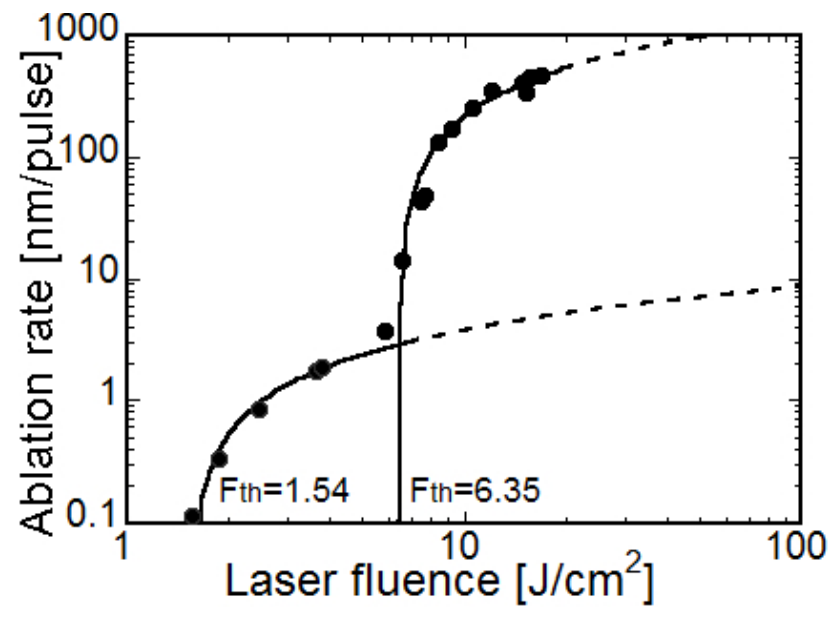

Fig. 4 Ablation rate dependence on laser fluence for Mo.

For nanosecond laser irradiation, the penetration length $\alpha^{-1}$ can generally be treated as the thermal diffusion length [29] because the laser pulse duration is much longer than the timescale of electron-phonon coupling (a few picoseconds for metals). The penetration length $\alpha^{-1}$ can be calculated easily from the physical constants of the material; for Mo, $\alpha^{-1}=1.49 \mu \mathrm{m}$. From the experimental data, the fitted logarithmic lines give $\alpha^{-1}=0.47 \mu \mathrm{m}$ for the high-fluence region and $0.002 \mu \mathrm{m}$ for the low-fluence region. The calculated penetration length $(1.49 \mu \mathrm{m})$ agrees with the experimentally determined one $(0.47 \mu \mathrm{m})$ at high 
fluence to within an order of magnitude. Therefore, ablation by high-fluence irradiation will occur thermally. By contrast, in the low-fluence region, the experimentally determined penetration length $(0.002 \mu \mathrm{m})$ is characterized well by the optical penetration depth $(0.007 \mu \mathrm{m})$. For the other metals considered herein, the relationship between the theoretical and experimental values of penetration depth $\alpha^{-1}$ was similar to that for Mo.

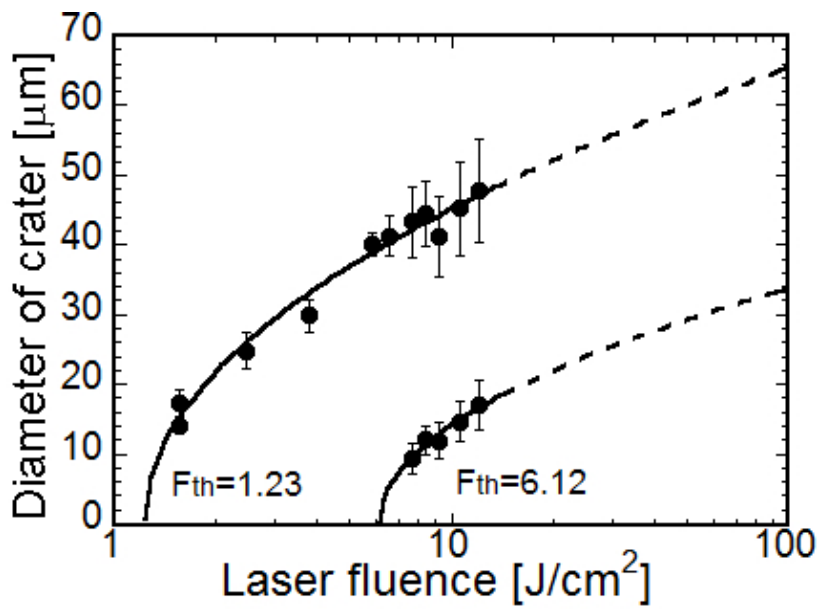

Fig. 5 Dependence of crater diameter on laser fluence for Mo.

The dependence of crater diameter on laser fluence is shown in Fig. 5. At laser fluences above $7 \mathrm{~J} / \mathrm{cm}^{2}$, the craters consisted of regions of deeper and shallower ablation. The diameter of each ablated region is plotted against laser fluence in Fig. 5. When a laser with a Gaussian beam profile was used as the ablation source, the dependence of crater diameter on laser fluence is given by Eq. (2) [26,30]:

$$
\Gamma=a \sqrt{\ln \left(F / F_{t h}\right)},
$$

where $\Gamma$ is the diameter of the crater $[\mu \mathrm{m}], a$ is the diameter of the laser beam on the sample surface $[\mu \mathrm{m}], F$ is the laser fluence of the ablation source $\left[\mathrm{J} / \mathrm{cm}^{2}\right]$, and $F_{\text {th }}$ is the ablation threshold $\left[\mathrm{J} / \mathrm{cm}^{2}\right]$. The curves fitted with Eq. (2) are the solid lines in Fig. 5. Two ablation thresholds can also be distinguished from the dependence of crater diameter on laser fluence. The obtained thresholds agree well with those obtained from the ablation rate dependence.

The ablation thresholds, the melting points, and the work functions [31] for $\mathrm{Ti}, \mathrm{Mo}, \mathrm{Pt}, \mathrm{Au}$, and $\mathrm{Al}$ are listed in Table 1. Similar tendencies were observed for other metals. It is found that the two ablation thresholds $F_{\text {th,H }}$ and $F_{\text {th, } \mathrm{L}}$ are independent of melting point and work function.
Table 1 Ablation thresholds, melting points $\left(T_{m}\right)$, and work functions (WF) for Ti, Mo, Pt, $\mathrm{Au}$, and $\mathrm{Al}$

\begin{tabular}{cccccc}
\hline & $\begin{array}{c}F_{\text {th, }} \\
{\left[\mathrm{J} / \mathrm{cm}^{2}\right]}\end{array}$ & $\begin{array}{c}F_{\text {th,H }} \\
{\left[\mathrm{J} / \mathrm{cm}^{2}\right]}\end{array}$ & $\begin{array}{c}F_{\text {th }}{ }^{*} \\
{\left[\mathrm{~J} / \mathrm{cm}^{2}\right]}\end{array}$ & $\begin{array}{c}T_{\mathrm{m}} \\
{[\mathrm{K}]}\end{array}$ & $\begin{array}{c}W F \\
{[\mathrm{eV}]}\end{array}$ \\
\hline $\mathrm{Ti}$ & 0.173 & 1.91 & 0.244 & 1933 & 3.57 \\
$\mathrm{Mo}$ & 1.54 & 6.35 & 1.46 & 2890 & 4.41 \\
$\mathrm{Pt}$ & 0.46 & 3.68 & 0.777 & 2045 & 5.63 \\
$\mathrm{Au}$ & 0.25 & 2.18 & 0.586 & 1337 & 5.32 \\
$\mathrm{Al}$ & 1.60 & 4.53 & 0.970 & 933.5 & 4.19 \\
\hline
\end{tabular}

*Threshold calculated with one-dimensional thermal diffusion model

\subsection{Relationship between measured and calculated ablation thresholds}

We compared two ablation thresholds with one calculated using a one-dimensional thermal diffusion model $[32,33]$. The calculated ablation threshold $F_{\text {th }}$ is given by

$$
F_{t h}=\frac{\left(T_{m}-T_{0}\right) \sqrt{\pi C_{i} k_{i}}}{2 A} \sqrt{\tau_{L}}
$$

where $T_{\mathrm{m}}$ is the melting point of the sample [K], $T_{0}$ is the initial temperature $[\mathrm{K}], C_{\mathrm{i}}$ is the heat capacity $\left[\mathrm{J} / \mathrm{cm}^{3} / \mathrm{K}\right], k_{\mathrm{i}}$ is the thermal conductivity $[\mathrm{W} / \mathrm{cm} / \mathrm{K}], \tau_{\mathrm{L}}$ is the laser pulse width [s], and $A$ is the absorption factor. The relationship between the measured and calculated ablation thresholds for each metal is shown in Fig. 6. It is found that the two ablation thresholds $F_{\text {th, } \mathrm{H}}$ and $F_{\text {th,L }}$ are related to the calculated threshold. In particular, a sufficiently good correlation is observed between the obtained low ablation threshold $F_{\text {th,L }}$ and the calculated threshold. Therefore, the low ablation threshold might be due to the excimer laser irradiation melting the metal. The experimental results suggest that, even at such extremely low ablation rates, melting plays an essential role in laser ablation.

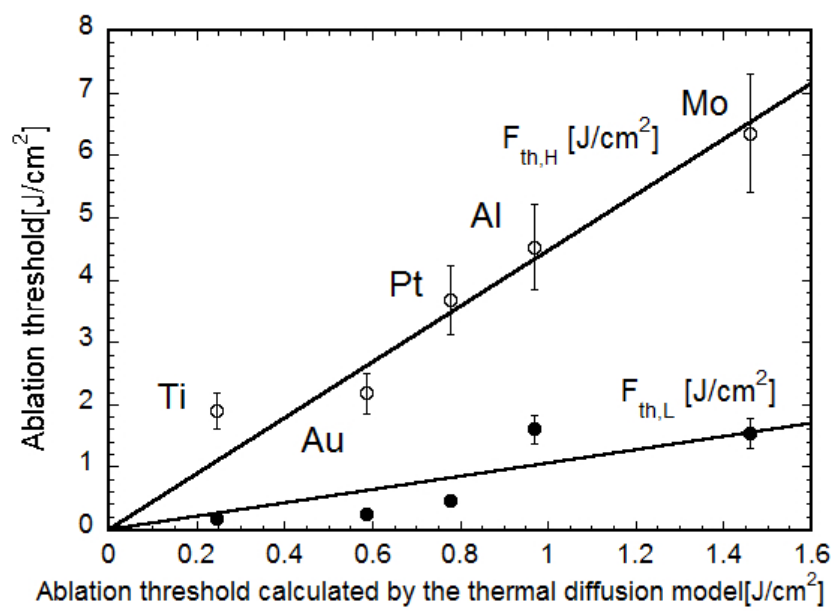

Fig. 6 Relationship between measured and calculated ablation thresholds for each metal. 


\section{Conclusions}

Ablation thresholds for the metallic elements Ti, Mo, Pt, $\mathrm{Au}$, and $\mathrm{Al}$ were measured with a $\mathrm{XeCl}$ excimer laser in the fluence range of $0.1-20 \mathrm{~J} / \mathrm{cm}^{2}$. The ablation thresholds were estimated from the dependence of ablation rate and the diameter of the crater produced by the laser irradiation on laser fluence. Two ablation thresholds obtained from the ablation rate dependence on the fluence agreed well with those obtained from the diameter dependence. The lower ablation threshold was related to the threshold calculated using a one-dimensional thermal diffusion model. The results suggested that even at such extremely low ablation rates, melting plays an essential role in the excimer laser ablation of metals.

\section{Acknowledgments}

We thank Mr. Y. Nishimura, Mr. K. Yamashita, and Mr. Y. Nishioka for their assistance with this work. This work was partially supported by the Collaborative Research Program of the Institute for Chemical Research, Kyoto University (grant \#2016-3).

\section{References}

[1] C. Geertsen, J. L. Lacour, P. Mauchien and L. Pierrard: Spectrochim. Act. B 51, (1996)1403.

[2] M. L. Sentis, P. Delaporte, W. Marine and O Uteza: Proc. SPIE., 3887, (2000)316.

[3] X. Liu and G. Mourou: Laser Focus World, August (1997)p.101.

[4] J. Young, J. Sipe, J. Preston and H. Vandriel: Appl. Phys. Lett., 41, (1982)261.

[5] S. Brueck and D. Ehlic: Phys. Rev. Lett., 45, (1982) 1678.

[6] I. Bozsoki, B. Balogh and P. Gordon: Opt. Laser Technol., 43, (2011)1212.

[7] M. Djouder, D. Deghiche, O. Lamrous and T. e. Itina: Appl. Surf. Sci., 258, (2012)2580.

[8] D. J. Orzi, F. C. Alvira and G. M. Bilmes: Appl. Phys. A, 110, (2013)735.

[9] G. Buccolieri, V. Nassisi, A. Castellano, A. Buccolieri and F. Vona: Appl. Surf. Sci., 272, (2013)55.

[10] D. Usmanov, K. Hiraoka, L. C. Chen and S. Ninomiya: Int. J. Mass Spectrom., 341, (2013)45.

[11] V. N. Lednev, S. M. Pershin, A. E. Ligachev, A. F. Bunkin, A. A. Ionin, S. I. Kudryashov, S. V. Makarov, A. A. Rudenko and R. A. Chmelnitsky: Spectrochim. Acta part B, 88, (2013)15.

[12] H. Sakamoto and K. Morioka: J. Laser Micro/Nanoeng., 8, (2013)45.

[13] S. J. Henley, I. Jurewicz, A. Dalton, M. Cann and D. Milne: Nanoscale, 6, (2014)946.
[14] L. M. Kukreja, S. Verma, D. A. Pathrose and B. T. Rao: J. Phys. D, 47, (2014)034015-1.

[15] S. Rung, A. Christiansen and R. Hellmann: Appl. Surf. Sci., 305, (2014)347.

[16] T. T. D. Huynh and N. Semmar: Appl. Phys. A, 116, (2014)1429.

[17] Y. Jin, W. Perrie, O. J. Allegre, G. Dearden, P. Harris and K. J. Abrams: Opt. Lasers Eng., 74, (2015)67.

[18] J. Roth, H-R. Trebin, A. Kiselev and D-M. Rapp: Appl. Phys. A, 122, (2016)500-1.

[19] A. Semerok, Chaleard, V. Detalle, J.L. Lacour, P. Mauchuen, P. Meynadier, C. Nouvellon, B. Salle, P. Palianov, M. Perdrix and G. Petite: Appl. Surf. Sci., 138139, (1999) 311.

[20] B. Salle, C. Chaleard, V. Detalle, J.L. Lacour, P. Mauchuen, C. Nouvellon and A. Semerok: Appl. Surf. Sci., 138-139, (1999)302.

[21] Etude de l'interaction laser- materiua appliquee a l'analyse elementaire des solides, B. Salle, doctoral theses, Universite de Orleans (1999).

[22] L. Tunna, A. Kearns, W. O’Neill and C. J. Sutcliffe: Opt. Laser Technol., 33(2001)135.

[23] D. W. Zeng, K. C. Yung and C. S. Xie: Appl. Surf. Sci., 217, (2003)170.

[24] M. Colina, C. Molpeceres, M. Morales, F. AllensPerkins, G. Guadano and J. L. Ocana: Surf. Eng., 27, (2011)414.

[25] M. Hashida, A. Semerok, O. Gobert, G. Petit and J. F. Wagner: Appl. Surf. Sci., 197-198, (2002)862.

[26] S. Nolte, C. Momma, H. Jacobes, A. Tunnermann, B. N. Chichikov, B. Wellegehausen and H. Welling: J. Soc. Am. B, 14, (1997)2716.

[27] M. Hashida, A. Semerok, O. Gobert, G. Petit and J. F. Wagner: Proc. SPIE, Nonresonant Laser -Matter Interaction (NLMI-10), 4423, (2001)178.

[28] K. Fujiwara, K. Takahashi, S. Cho, H. Kumagai, K. Midorikawa and M. Obara: Proc. SPIE, High Power Laser Ablation II, 3885, (2001)509.

[29] P. B. Corkum, F. Brunel, N. K. Sherman and T. Srinivasan-Rao: Phys. Rev. Lett., 61, (1988)2886.

[30] J. Jandeleit, G. Urbasch, H. D. Hoffmann, H. G. Treush and E. W. Kreulz: Appl. Phys. A, 63, (1996)117.

[31] R.C. Weast: "CRC Handbook of Chemistry and Physics", 68 ${ }^{\text {th }}$ Ed., (1987-1988)E377.

[32] B. N. Chichikov, C. Momma, S. Nolte, F. von Alvensleben and A. Tunnermann: Appl. Phys. A, 63, (1996)109.

[33] M. Sparks and E. Loh, Jr: J. Opt. Soc. Am., 69, (1979).

(Received: June 30, 2017, Accepted: January 13, 2018) 